\section{Tracing the origin and differentiation of the enstatite achondrite parent bodies using $\mathrm{Cr}$ isotopes}

\section{KE ZHU ${ }^{1}$, FRÉDÉRIC MOYNIER ${ }^{2}$, MARTIN SCHILLER ${ }^{3}$, HARRY BECKER ${ }^{1}$, JEAN-ALIX BARRAT ${ }^{4}$ AND MARTIN BIZZARRO $^{2,3}$}

${ }^{1}$ Freie Universität Berlin

${ }^{2}$ Université de Paris, Institut de physique du globe de Paris

${ }^{3}$ University of Copenhagen

${ }^{4}$ UBO-IUEM

Presenting Author: zhu@ipgp.fr

Enstatite achondrites (including aubrites) have similar isotope compositions to the Earth-Moon system for most of the elements (e.g. O). However, the origin and differentiation of enstatite achondrites and their parent bodies remain poorly understood. This work reported both the mass-independent (MC-ICP-MS [1] and TIMS [2]) and mass-dependent (MC-ICP-MS [3]) Cr isotope data for 10 enstatite achondrites, including 8 aubrites, Itqiy (EH7-an) and one enstatite-rich clast in Almahatta Sitta [4]. Combined with literature [5], our data provide insights into the origin $\left(\varepsilon^{54} \mathrm{Cr}\right)$ and the formation processes $\left(\delta^{53} \mathrm{Cr}\right)$ and timing $\left(\varepsilon^{53} \mathrm{Cr}\right)$ of the enstatite achondrite parent bodies.

The $\varepsilon^{54} \mathrm{Cr}$ values define three groups of meteorites (Figure 1) that represent: the main-group aubrite parent body with $\varepsilon^{54} \mathrm{Cr}$ of $0.06 \pm 0.12(2 \mathrm{SD}, \mathrm{N}=7)$, Shallowater parent body with $\varepsilon^{54} \mathrm{Cr}=$ $-0.12 \pm 0.04$ and Itqiy parent body with $\varepsilon^{54} \mathrm{Cr}=-0.26 \pm 0.03$ $(2 \mathrm{SD}, \mathrm{N}=2)$. This is consistent with their different $\delta^{53} \mathrm{Cr}$ values: $0.24 \pm 0.03 \%$, $0.10 \pm 0.03 \%$ and $-0.03 \pm 0.03 \%$, respectively (Figure 2).

While variable, the $\delta^{53} \mathrm{Cr}$ value are all higher in aubrites than in any group of chondrites (Figure 2). This most likely represents stable isotope fractionation of isotopically light $\mathrm{Cr}$ sulphide during core formation, resulting in an isotopically heavy mantle.

The aubrite samples record heterogeneous distribution of $\mathrm{Mn}$ and $\mathrm{Cr}$. The ${ }^{53} \mathrm{Mn}-{ }^{53} \mathrm{Cr}$ correlation for the main-group aubrites (except Bustee) is interpreted to reflect mixing of different proportions of sulfides and silicates, consistent with $\mathrm{Cr}$ stable isotope variation. The absence of internal ${ }^{53} \mathrm{Mn}-{ }^{53} \mathrm{Cr}$ isochrons for individual main-group aubrite samples implies that they underwent metamorphic redistribution of $\mathrm{Mn}$ and $\mathrm{Cr}$ after ${ }^{53} \mathrm{Mn}$ became extinct, possibly following a disruption event of the main-group aubrite parent body, which could reset the internal $\mathrm{Mn}-\mathrm{Cr}$ isochrons.

\section{References:}

1. Zhu, K., et al. (2021), GCA, in press.

2. Zhu, K., et al. (2020), ApJL, 894, L26.

3. Zhu, K., et al. (2021), GCA. 293, 598-609.

4. Harries, D. and Bischoff A. (2020), EPSL, 548, 116506.

5. Shukolyukov, A. and Lugmair G.W. (2004), GCA, 68, 2875-2888
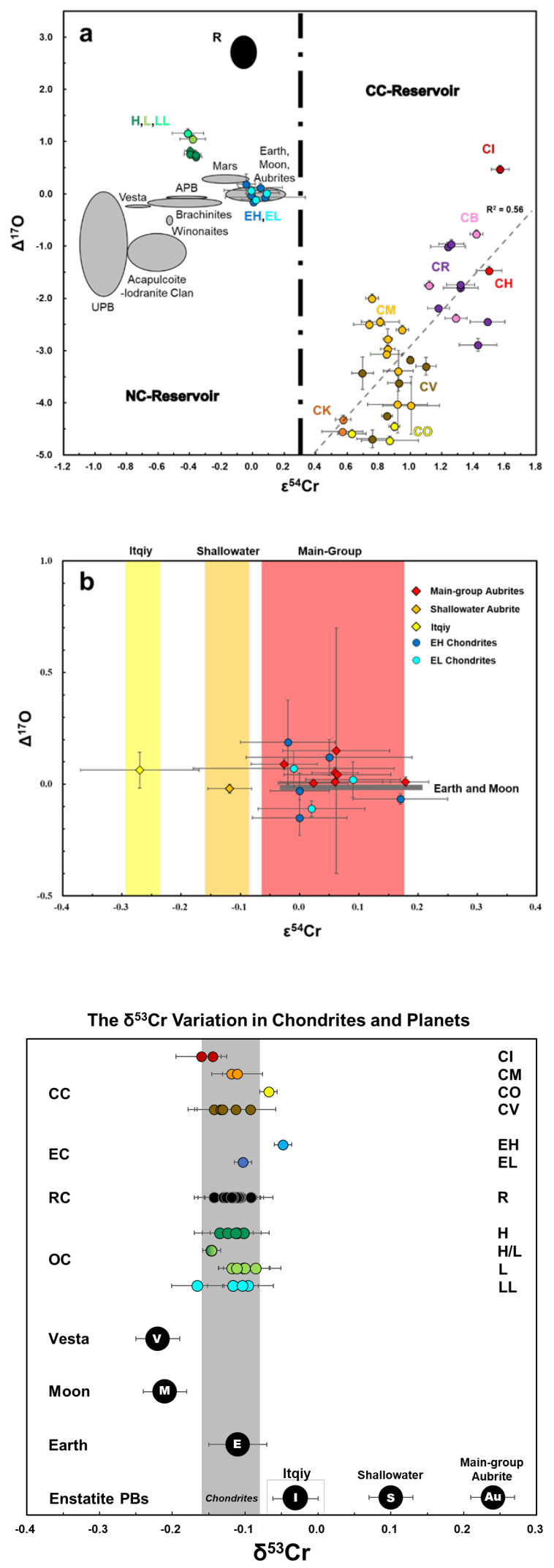